2019-02

\title{
Climate Change Communication in the United Kingdom
}

\author{
Anderson, Alison
}

http://hdl.handle.net/10026.1/12182

10.1093/acrefore/9780190228620.013.458

Oxford Research Encyclopedia of Climate Science

Oxford University Press

All content in PEARL is protected by copyright law. Author manuscripts are made available in accordance with publisher policies. Please cite only the published version using the details provided on the item record or document. In the absence of an open licence (e.g. Creative Commons), permissions for further reuse of content should be sought from the publisher or author. 


\section{Climate Change Communication in the United Kingdom}

Alison Anderson

\section{Summary}

There is a comparably lengthy history of climate change communication research in the UK that can be traced back to the late 1980s. As is the case for media research in general, most attention has historically focused on print media and elite newspapers in particular. The British public appears to have a rather ambivalent response to climate change and most people do not view it as a pressing threat. Whilst surveys suggest that the majority of citizens believe that climate change is occurring, and is at least partly caused by human activity, sceptic views have received greater prominence in the mainstream media than in many other comparable countries. Climate deniers have received considerable space on the opinion pages of some right-leaning British newspapers. This is no doubt linked to vigorous denial campaigns mounted by climate sceptic think tanks in the UK. The left-of-centre Guardian newspaper (and its counterpart Sunday edition, The Observer) has led the way on climate change reporting, far exceeding the amount of space devoted to the topic by other print news outlets, yet it has one of the lowest readerships. While traditional media remain important agenda-setters, online and social media are increasingly significant sources of news especially for younger individuals. Future climate communication scholarship should play a vital role in informing stakeholder strategies and better understanding the complex linkages between media framing, political agendas, and public perceptions.

Keywords: climate change, communication, UK, media, public opinion, scepticism, Brexit

\section{The UK Context}

The UK is a very interesting case as it has played an important role in shaping climate change action in Europe. The 2008 Climate Change Act represented the first global legally binding national target to be set by a country. Since the global economic recession began to bite, however, green initiatives were one of the first things to be cut from the policy agenda, and cutbacks have also impacted on environmental journalism. A report by the UK Government Science and Technology Committee in 2014 found sparse evidence of co-ordination amongst Government, government agencies and public bodies on communicating climate science, despite the existence of policies to mitigate and adapt to climate change at national and regional level (House of Commons Science \& Technology Committee, 2014). Against the recommendations of the Statutory Committee on Climate Change that a single department should lead the way on climate communication, the UK Government suggested in October 2015 that other agencies should provide information about specific climate change impacts. However, funding to agencies such as Climate UK, which supports a network of 12 partnerships with over 10,000 stakeholders, was halved (Ward, 2015). The 2016 EU national referendum, where the British public voted to leave the European Union, has cast the 
direction of climate change policy into further doubt and climate hardly figured in the 2017 General Election.

There is a relatively long history of research into climate change communication in the UK, beginning in the late 1980s. A number of factors have played a role in influencing public engagement with the issues.

\section{Socio-political trends over time}

The socio-political history of climate change communication in the UK can be divided into five main phases.

\section{Phase 1: Growth in Basic Awareness (Late 1980s to early 1990s)}

The first sharp spike in coverage in British national daily newspapers first occurred in the late 1980s as the issues became increasingly politicized (Anderson, 1997; Anderson, 2014: Carvalho \& Burgess, 2005). The record high temperatures in the US during the summer of 1988 and the ensuing drought became a major news story when James Hansen testified to US Congress that he was $99 \%$ confident that a long-term trend towards global warming was occurring. Amid growing evidence of rising public interest in environmental issues, that September former British Prime Minister Margaret Thatcher made a 'green' speech to the Royal Society pushing the issue further up the agenda (Anderson, 1997). In the early part of this phase a scientific discourse dominated with climate scientists appearing as the major news sources in the UK national press. While newspaper articles generally did not question that global warming was occurring, the risks tended to be de-emphasized. The problem was framed in narrow scientific terms with few articles pursuing broader socio-political aspects (Carvalho \& Burgess, 2005). However, following Margaret Thatcher's speech, political actors became more heavily quoted in relation to climate change and scientists were no longer the exclusive definers of the issue (Carvalho \& Burgess, 2005).

\section{Phase 2: Economic Slump, Political Inertia and Climate Fatigue (Early to mid-1990s)}

There was a marked fall in UK press coverage of climate change between 1991 and 1996 as political interest waned, despite a short blip in 1995 when the IPCC report was released (Anderson \& Gaber, 1993a, 1993b; Anderson, 1997; Carvalho \& Burgess, 2005). Major factors contributing to this significant decline in coverage included the economic recession and political inertia which led to difficulties in sustaining the newsworthiness of the issue.

\section{Phase 3: Climate Activism and Mainstreaming on the International Policy Agenda (Mid 1990s to Early 2000s)}

A second spike in newspaper coverage took place between 1997 and 2003, as the impacts of climate change were brought closer to home (Carvalho \& Burgess, 2005). Important policy events such as the Kyoto Climate Summit in 1997, together with extreme weather events in 
Asia, Canada and the United States generated more coverage (Carvalho \& Burgess, 2005). Climate activism also played an important role during this period.

\section{Phase 4: The Rise of UK Green Hero Discourse (Early 2000s to 2008)}

The G8 Summit in 2005 and the coming into force of the Kyoto Protocol propelled climate change up the political agenda. In 2006 there was four times as much coverage of climate change issues in the UK elite national newspapers than there was in 2003. The passing of the Climate Change Act in 2008 institutionalized the issue and the subject matter was just as likely to be covered using a business/policy frame as a scientific frame (Philo \& Happer, 2013). Romsdahl et al. (2017) examined newspaper articles in the British quality press over the period 2004-2014 and found a substantial increase in newspaper coverage of climate change from 2004 until mid-2007. This period in the lead up to the passing of the Climate Change Act, as well as the publication of the IPCC Fourth Report on Climate Change, was marked by what they call a 'green hero' discourse which portrayed the UK government as heroic in its efforts to tackle climate change.

\section{Phase 5: Climate Change Slips down the Political Agenda and the Return to a Problem Solving Discourse (2008 onwards)}

The US stock market crash of 2008 and the global economic recession marked a period where there was a marked slump in the UK press coverage of climate change, with the exception of a spike that occurred at the end of 2009 with the University of East Anglia Climatic Research Unit email controversy, which became referred to as 'Climategate', and the run up to COP15 (Romsdahl et al, (2017). Despite the passing of the Climate Change Act, with binding requirements to reduce emissions domestically by $80 \%$ in 2050 from 1990 levels, the UK government shifted away from addressing climate change through a sustainability discourse and returned to a problem-solving discourse, focusing on industrialism and economic growth. Political attention focused increasingly on nuclear energy and fracking shale gas. Nuclear power is a significant source of energy generation in the UK, but while there has been a history of framing nuclear power as helping to provide a 'solution' to climate change public opinion research has consistently suggested that citizens would rather opt for renewable energy, and the Fukishima accident did little to dent this preference in the long term (Doyle, 2011a; Pidgeon et al., 2008; Steentjes et al., 2017). Cross reference to Shirley S. Ho (2016) 'Communicating about Nuclear Energy and Climate Change', Oxford Research Encyclopaedia DOI: 10.1093/acrefore/9780190228620.013.440

Romsdahl et al. (2017) found that between 2008 and 2010 there was a significant drop in attention to environmental protection issues among all the sampled British quality newspapers, although this was less evident in The Guardian. Aside from a spike in coverage in 2009 with Climategate and COP15 there was a marked decline in press coverage from 2008 until 2014, when the study concluded. In December 2015 the UK signed and ratified the Paris Accord at UNFCC COP21, pledging to keep global temperature increase "well below $2^{\circ} \mathrm{C}$ " and to aim for limiting the temperature increase to $1.5^{\circ} \mathrm{C}$, resulting in another peak in coverage which was especially significant for The Guardian \& Observer (see Figure 1). 
Note: The left-leaning Guardian has consistently been shown to carry the greatest number of items on climate change but it has one of lowest readerships (Hope, 2014).

Figure One: UK Newspaper Coverage of Climate Change or Global Warming, 2000-2018

\section{0-2018 United Kingdom Newspaper Coverage of Climate Change or Global Warming}

Click and drag in the plot area to zoom in

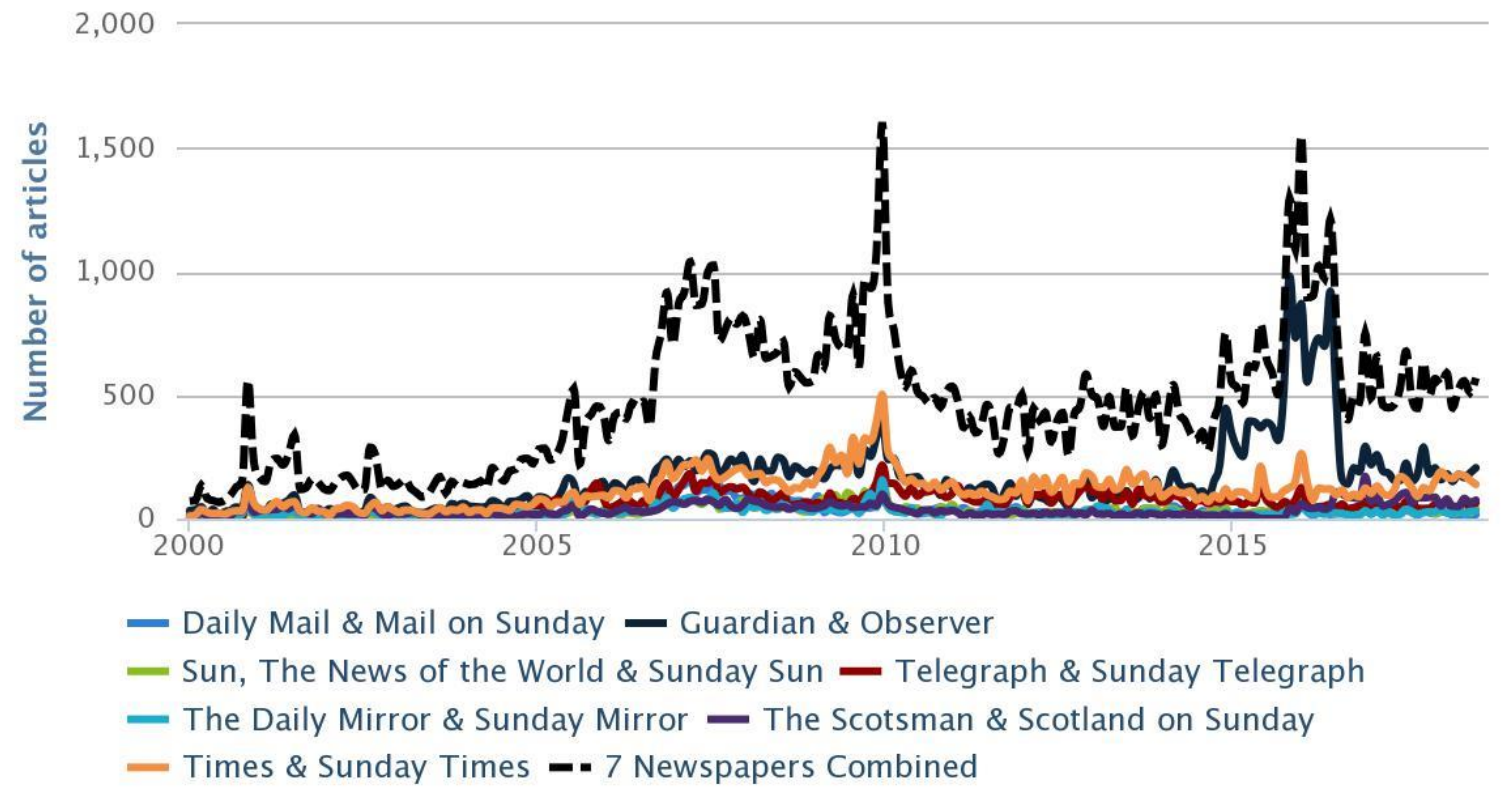

Boykoff, M., Daly, M., McAllister, L., McNatt, M., Nacu-Schmidt, A., Oonk, D., and Pearman, O. (2018). United Kingdom Newspaper Coverage of Climate Change or Global Warming, 2000-2018. Center for Science and Technology Policy Research, Cooperative Institute for Research in Environmental Sciences, University of Colorado, Web.

Significant spikes in press coverage tend to occur around major international climate change conferences in Europe: Copenhagen in November/December, 2009, Bonn in October, 2014, Paris in November/December 2016, and Bonn in May, 2016. However, popular newspapers such as The Sun clearly view such events as bearing little newsworthiness.

Following the Brexit decision on 23rd June 2016 for Britain to leave the EU and the 2017 General Election, in which climate change hardly figured as an issue, coverage returned to similar levels that were seen in 2007.

\section{Research on Climate Change Communication in the UK}

In a meta-analysis of publications over the period 1957 to 2010 Schäfer \& Schlichting (2014) found a significant amount of scholarly attention has been devoted to studying climate 
change in the media, with the UK having the highest share in Europe. The vast bulk of these studies focused on print media. Indeed two-thirds of all analysed material in the whole sample across countries was print media. Most attention focused on national 'quality' broadsheets. From the start scholarly work had a strong interdisciplinary flavour cutting across Sociology, Human Geography, Political Science and Media Studies. A handful of studies in the early 1990s focused on examining media coverage of environmental issues including, as it was widely referred to then, the 'greenhouse effect' or 'global warming' (Anderson, 1991; Cottle, 1993; Hansen, 1993). Much of this early scholarly interest focused on the impact of news values in shaping differential amounts of attention devoted to competing environmental issues, and inequalities of access among news sources. Cottle provided one of the few studies in the 1990s examining television coverage of environmental issues including global warming. His research centred on national and regional TV news programming in the UK and the ways in which particular news formats encourage differential frames and patterns of news sourcing. Anderson (1991) and Hansen (1993) focused on national press coverage of environmental issues and the strategies employed by environmental NGOs in seeking to shape the news agenda.

A combination of methods has been applied including quantitative content analysis (e.g. Anderson, 1991; 1997) and discourse analysis (e.g. Carvalho, 2007; Doulton \& Brown, 2009; Hansen, 1993). Carvalho and Burgess undertook important foundational work in uncovering the influence of ideology on journalistic representations of climate science in the elite British press (Carvalho \& Burgess, 2005; Carvalho, 2007). One of the first major quantitative content analysis studies to focus in depth on the representation of climate change in the British press was undertaken by US Geographer Max Boykoff. He examined the impact of journalistic norms on US and UK press coverage of climate science, concluding from his quantitative content analysis that there was no major divergence from the scientific consensus that humans contribute to climate change in the case of UK national 'quality' newspapers (Boykoff, 2007). However, in a later study he found that this was not the case for red top (mass market) British newspapers over the period 2000-2006 which has a substantially larger readership (Boykoff, 2008; Boykoff \& Mansfield, 2008). Subsequent studies have also analysed UK press coverage of climate change during climate summits (e.g. Painter, 2010).

Until around 2007 most studies focused on textual representations of climate change in the British media and few researchers examined visual constructions. Doyle (2007) undertook an important piece of research analysing the history of climate change communication produced by Greenpeace since the early 1990s focusing on their use of images and photographic evidence of climate impact (see also Doyle, 2011b). She highlighted how traditionally science conceptualised nature in ways which discouraged viewing climate change as invisible, incremental, and temporally complex. Her analysis suggested that the imagery used by NGOs such as Greenpeace tended to reinforce such conceptualisations, seeing humans as disconnected from nature. Another such study was undertaken by Hansen and Machin (2008) who performed a critical discourse analysis of a sample of visual materials in Getty image bank, widely used to source images in UK reporting on climate change. The emphasis in the sample of 600 images from the Getty Green collection was on the beauty and fragility of 
nature. The environment was abstract and decontextualized, models were generic and settings decontextualized and there was no representation of causes, effects or solutions. One of the first studies to have centred on the use of climate change imagery in the British press was conducted by Smith and Joffe (2009). Their analysis of UK press imagery of climate change found a strong tendency to personify the issue through pictures of melting ice caps and polar bears, or images of celebrities and political leaders. More recent work by O'Neill has investigated the relationship between visual representations of climate change and people's perceptions of the issue in the UK through focus groups, interviews and surveys (O'Neill, 2013; O’Neill \& Nicholson-Cole, 2009). Personification was still found to be a dominant theme in the UK newspaper visual imagery as in many other parts of the globe. However, the UK's visual coverage highlighting impacts on polar and glacial regions was found to be quite different to that in Australia and the US. Cross reference to: Hansen, A. (2017). Methods for Assessing Visual Images and Depictions of Climate Change. Oxford Encyclopaedia of Climate Science: Oxford University Press.

http://climatescience.oxfordre.com/view/10.1093/acrefore/9780190228620.001.0001/acrefore -9780190228620-e-491.

Studies of online media coverage of climate change and the UK context have emerged only relatively recently (for example, Gavin, 2009; Gavin \& Marshall, 2011; Newman et al., 2016). Given the growing importance of digital and social media as a source of information on climate change, especially for young people, this is a very welcome development (Newman et al., 2016; Painter et al., 2016; Whitmarsh, 2010). These outlets offer a space for constructing new narratives around climate change. A study undertaken by researchers at Loughborough University found that in the lead up to the Brexit vote only $0.5 \%$ of newspaper coverage referred to environmental issues (Deacon et al., 2016). Research undertaken by Painter et al. (2016) found that the new digital born news outlets such as the Huffington Post and Buzzfeed feature among the most popular online news sources for those citizens in the UK who are highly interested in environmental news. These outlets were found to include little mention of climate scepticism, or where they did they treated it with humour, and were more likely to include blogs written from an environmental activist perspective than mainstream media

\section{Climate Scepticism and Public Opinion}

Climate sceptics have mobilized in the UK to seek to influence public opinion against taking concerted action on climate change - for example, the Global Warming Policy Foundation (GWPF) which was established at the end of 2009 (Painter \& Gavin, 2016). The print media in the UK is divided ideologically, with the most prolific climate sceptics writing predominantly in the right-wing newspapers such as the Daily Mail and the Daily Telegraph. Painter (2011) found what he described as: "A strong correspondence between the political perspective of a British newspaper and the degree of prevalence of sceptical voices" (2011: 109) with two right-leaning newspapers (the Express and the Daily Mail) publishing almost half of all the corpus of sampled articles (over the period 2007 and 2011) in news and opinion columns containing sceptical voices. However, he rejects a simple reductionism and points 
out that The Sun and The Times are politically conservative and yet in terms of their inclusion of sceptical views were more akin to the left-leaning publications.

A later study undertaken by Painter and Gavin analysed climate scepticism in all the major British national daily newspapers, and their Sunday counterparts, between 2007 and 2011, but this time examining three important phases of coverage linked to key events and with different defining characteristics in terms of the volume of coverage and the justification for including sceptic voices. The first phase was 1 February- 30 April 2007, the second was 18 November-19 February 2010, and the final phase was 19 November 2010-18 February 2011. In the first phase there were high volumes of coverage but little editorial justification for sceptical voices. In the second phases there was high volume but strong editorial justification for such voices. Finally, in the third phase, there was a low volume of articles and less justification for the inclusion of sceptics compared with the former two phases. Painter and Gavin found a significant increase in the number of sceptical voices in the second and third periods compared to the first. Studies have shown that historically left-leaning newspapers in the UK have tended to emphasize that climate change is happening, whereas conservative newspapers have often presented the science as uncertain (Carvalho, 2007; Ereaut \& Segnit, 2006, Schmid-Petri \& Arlt, 2016). Although Painter and Gavin found some evidence to support this, on the whole, sceptical views tended to be confined to the opinion pages of newspapers across their sample.

Various types of scepticism can be discerned. First there is scepticism about the scientific evidence for climate change which can be broken down into: denial that climate change is occurring (trend scepticism), rejection of the anthropogenic causes of climate change or whether there is sufficient evidence to identify the cause (attribution scepticism), and finally acceptance of the reality of climate change but scepticism over viewing the consequences as harmful (impact scepticism). In addition to this, a further type of scepticism doubts the effectiveness of action on climate change, or centres on the view that no binding regulations are needed and the free market should prevail in order to protect the economy (response scepticism) (Capstick \& Pidgeon, 2014; Rahmstorf, 2004). In addition to this there are also a number of other possible ways to classify sceptical arguments (see Howarth \& Sharman, 2015; van Rensburg, 2015). In a content analysis study comparing climate change coverage in the UK, Germany and Switzerland, Schmid-Petri (2017) examined a sample of left and right leaning British national daily newspapers between 1 June 2012 and 31 May 2013. She found that trend or attribution scepticism was not particularly prominent in UK conservative leaning newspapers. However, there does appear to be a relationship between impact and response scepticism and the ideological orientation of news outlets, as right-leaning newspapers were found to be more likely to carry articles containing these types of arguments. One explanation for this may be that given much greater scientific consensus about the existence of global warming scepticism tends to centre on emphasizing the positive consequences that may be associated with climate change and questioning the necessity for binding regulations. Trend and attribution scepticism featured particularly in commentaries or opinion features of conservative newspapers, whereas impact scepticism was mostly found in 
news articles in conservative outlets. Response scepticism was more evenly distributed between news and opinion pieces.

Public opinion on climate change has fluctuated considerably over time in the UK and has been influenced by a variety of factors including climate fatigue, economic downturn, weather events, media attention to the issues, and high profile political events. In terms of the most important issues seen as facing Britain in 2017 climate change does not figure very strongly and concerns about immigration and the economy dominate. The public appear to have a rather ambivalent response to climate change, a mixture of hope, fear and outrage but few exhibiting great levels of concern (Steentjes et al., 2017; Pidgeon, 2012). A survey undertaken in 2016 found that compared with people in Germany, Norway and France, participants in the UK seemed to be the least worried about climate change, with only $20 \%$ indicating they are very or extremely worried and $38 \%$ responding they are not very worried or not worried at all. Around a third of respondents in the UK thought a strong majority of scientists (over 80\%) agree on anthropogenic climate change but 58\% thought that most scientists (over 50\%) agree. Just over half of respondents in the UK (58\%) agreed that as a nation the UK could make a difference when it comes to climate change (Steentjes et al., 2017). As with a number of other countries such as the US and Australia, political cleavages on climate change are apparent in the UK. Citizens on the left of the political spectrum tend to express greater belief in, concern about, and support for action on climate change than citizens on the right (McCright et al., 2015). Public opinion surveys in the UK also suggest that older citizens who are politically conservative are more likely to be sceptical about the reality of climate change, and men are more likely to be sceptics than women (Poortinga et al., 2011, Whitmarsh, 2011). Poortinga et al. (2014) found an increase in trend scepticism among British citizens from 4 per cent in 2005 to 15 per cent in 2010 and 19 per cent in 2013. Fewer agreed with the statement "My local area is likely to be affected by climate change" in 2013 (47 per cent) compared to 2010 (53 per cent). While some have suggested a link between Climategate and increased distrust of climate scientists, a UK poll commissioned for the BBC at the beginning of 2010 found no evidence that the media attention surrounding Climategate had led to more people reporting reduced levels of belief about the risks of climate change, than reported higher levels of beliefs as a consequence (BBC/Populus, 2010).

There is some evidence to suggest that those individuals who were directly impacted by the 2013/14 floods in the UK exhibited higher levels of personal and local area threat from climate change (Demski et al., 2017). Research also suggests that values, membership of cultural groups, and political ideologies steer the information that individuals seek and shapes public interpretations of climate change (Kahan et al., 2011). An extensive analysis of trends in public opinion undertaken by Cardiff University suggests that the most significant influences are the state of the economy and the position of the issue on the political agenda:

"While experiences of anomalous weather and other events (e.g., The Day after Tomorrow; Fukushima; Climategate) appear to have exerted some influence on public perceptions (or, most often, perceptions of a sub-group of the population), time series analyses that take into account a range of possible explanatory factors (e.g., weather, socioeconomic factors, and 
political actions) indicate the economic downturn and political events have been particularly influential." (Capstick et al., 2015: 53).

Some focus group research has been undertaken in the UK examining how UK citizens negotiate new information on climate change in response to existing beliefs, perceptions and behavioural patterns. The longitudinal study over the period 2011-2014 found that discussions and news reporting on climate-change scenarios tended to strengthen rather than change UK focus group participants' pre-existing views. Those who had been the least exposed to information were the most likely to be open to reassessing their opinions (see by Philo and Happer, 2013; Happer \& Philo, 2016). However, despite some behavourial changes occurring for a few participants over the study period there remained a significant valueaction gap. There was widespread lack of trust in decision-makers to take action and individual citizen behaviours were not seen as making a difference. The lack of media attention was also seen as a significant barrier:

"The sense of not knowing who or what to trust in terms of the most effective course of action, rooted in the proliferation of media opinions and arguments, continued to be cited as a significant barrier to action. It was further compounded by the lack of attention to climate change across media which led people to de-prioritise it in their own minds" (Happer \& Philo, 2016: 146)

Beliefs about individual and collective agency are likely to prove central in addressing climate change in the Trump era. Neoliberal thinking has tended to place the solution purely in the hands of individual citizen actors rather than tackling more systemic issues. This has been a particularly pervasive ideology in the UK with the Thatcher government's emphasis on individualism, deregulation, and privatisation of public services.

\section{Future Directions}

The UK has played an important role in shaping European action on climate change. However, over recent years the UK government has limited financial support for renewable energy projects and rejected stronger binding targets for and energy efficiency and renewable energy generation. In the wake of Brexit the future implications for UK and EU climate policy remains to be seen. It is unclear whether the UK will remain a member of the EU Emissions Trading System.

It is vital that academic scholarship bridges the gap between research and practice. Existing scholarship on climate change communication in the UK has informed the work of Climate Outreach (formerly known as COIN) which provides an important vehicle for promoting public engagement. Future climate communication scholarship should play a key role in informing stakeholder strategies and better understanding the complex inter-relationship between media framing, political agendas and public perceptions. Whilst many strides have been made over recent decades there are still notable gaps and shortcomings that need to be filled. 
Future studies should examine a broader range of media beyond the mainstream press. Television news is an important source of information on climate change in the UK and is highly trusted as accurate and authoritative especially among people of 55 years age and older (Gavin, 2017; cross reference to Gavin 'TV and Cable News Coverage of Climate Change', Oxford Encyclopedia of Climate Change

http://climatescience.oxfordre.com/view/10.1093/acrefore/9780190228620.001.0001/acrefore -9780190228620-e-360 Painter et al., 2016). However, the number of people saying that online news is their main source is now roughly equal to TV, and the gap is closing (Painter et al., 2016. Two-thirds of those between the ages of 18-24 state that online is their main source of news (Newman et al., 2016). There is a need to examine how television and online media are informing the British public and how different messages resonate with various sections of the public.

There is also much more scope to explore visual representations of climate change particularly given the importance placed on video and graphics by the new digital players (Anderson, 2011; 2014). More research also needs to focus on analysing and evaluating stakeholder visualizations of climate change and their impact on public engagement. There are opportunities to use innovative methods such as photo-elicitation and eye tracking technology to understand better how individuals make sense of visual material, the representation of uncertainty, and what draws their attention.

Finally, ethnographic studies of news sources have tended to focus on environmental NGOs and scientists, with some exceptions, and little research has examined politicians or policymakers (see Anderson, 2009). While there is an emerging body of literature that examines how business and political parties are seeking to actively shape environmental news (Davis, 2007; Schlichting, 2013), few studies have focused on industry as a news source in environmental news reporting (Hansen, 2015).

\section{$\underline{\text { References }}$}

Anderson, A., (1991). Source strategies and the communication of environmental affairs. Media, Culture, and Society, 13 (4), 459-476.

Anderson, A. (1997). Media, culture and the environment. London: Routledge.

Anderson, A. (2009). Media, politics and climate change: Towards a new research agenda. Sociology Compass, 3(2), 166-182.

Anderson, A. (2011). Sources, media and modes of climate change communication: The role of celebrities. Wiley Interdisciplinary Reviews: Climate Change, 2(4), 535-546.

Anderson, A. (2014). Media, environment \& the network society. Basingstoke, U.K.: Palgrave. 
BBC/ Populus (2010, February). BBC Climate Change poll. Available at: http://news.bbc.co.uk/nol/shared/bsp/hi/pdfs/05_02_10climatechange.pdf (Accessed July 2017).

Boykoff, M. T. (2007). Flogging a dead norm? Media coverage of anthropogenic climate change in the United States and United Kingdom, 2003-2006. Area, 39, 470-481.

Boykoff, M.T. (2008). The cultural politics of climate change discourse in UK tabloids. Political Geography, 27, 549.

Boykoff, M. T., \& Mansfield, M. (2008). 'Ye Olde Hot Aire': Reporting on human contributions to climate change in the UK tabloid press. Environmental Research Letters, 3(2), 024002.

Capstick, S. B., \& Pidgeon, N. F. (2014). What is climate change scepticism? Examination of the concept using a mixed methods study of the UK public. Global Environmental Change, 24, 389-401.

Capstick, S., Whitmarsh, L., Poortinga, W., Pidgeon, N., \& Upham, P. (2015). International trends in public perceptions of climate change over the past quarter century. Wiley Interdisciplinary Reviews: Climate Change, 6(1), 35-61.

Carvalho, A. (2007). Ideological cultures and media discourses on scientific knowledge: Rereading news on climate change. Public Understanding of Science, 16(2), 223-243.

Carvalho, A., \& Burgess, J. (2005). Cultural circuits of climate change in the UK broadsheet newspapers, 1985-2003. Risk Analysis, 25(6), 1457-1470.

Cottle, S. (1993). 'Mediating the environment: Modalities of TV news ', in A. Hansen (ed.) The mass media and environmental Issues. Leicester: Leicester University Press, 107-133.

Davis, A. (2007). The mediation of power: A critical introduction, London: Routledge.

Deacon, D., Harmer, E., Downey, J., Stanyer, J., \& Wring, D. (2016). UK news coverage of the 2016 EU Referendum. Report 5 (6 May-22 June 2016).

https://dspace.lboro.ac.uk/dspacejspui/bitstream/2134/23822/3/CRCC\%20Report5\%20final.pdf accessed 19 July 2017.

Demski, C., Capstick, S., Pidgeon, N., Sposato, R. G., \& Spence, A. (2017). Experience of extreme weather affects climate change mitigation and adaptation responses. Climatic Change, 140(2), 149-164.

Doulton, H., \& Brown, K. (2009). Ten years to prevent catastrophe?: Discourses of climate change and international development in the UK press. Global Environmental Change, 19(2), 191-202.

Doyle, J. (2011a). Acclimatizing nuclear? Climate change, nuclear power and the reframing of risk in the UK news media. International Communication Gazette, 73(1-2), 107-125. 
Doyle, J. (2011b). Mediating climate change. Aldershot, U.K.: Ashgate.

Doyle, J. (2007). Picturing the clima(c)tic: Greenpeace and the representational politics of climate change communication. Science as Culture, 16, 129-50.

Ereaut, G., \& Segnit, N. (2007). Warm Words II: How the climate story is evolving and the lessons we can learn for encouraging public action. London: Institute for Public Policy Research.

https://www.ippr.org/files/images/media/files/publication/2011/05/warmwordsfull_1596.pdf

Ereaut G., \& Segnit N. (2006). Warm Words: How are we telling the climate change story and can we tell it better? London: Institute for Public Policy Research.

http://www.ippr.org.uk/publicationsandreports/publication.asp?id=485

Gavin, N. (2009). 'The web and climate change politics'. In Boyce, T., \& Lewis, J. (Eds.) Climate change and the media. Oxford: Peter Lang, 129-142.

Gavin, N.T., \& Marshall, T. (2011). Mediated climate change in Britain: Scepticism on the web and on television around Copenhagen. Global Environmental Change, 21, 1035.

Gavin, N. (2017). TV and cable news coverage of climate change. Oxford Research Encyclopaedia

Hansen, A., \& Machin, D. (2008). Visually branding the environment: climate change as a marketing opportunity. Discourse Studies, 10, 777-794.

Hansen, A. (2015). Promising directions for environmental communication research, Environmental Communication, 9 (3), 384-39.

Hansen, A. (1993). Greenpeace and press coverage of environmental issues, in: A. Hansen (Ed.) The mass media and environmental issues. Leicester: Leicester University Press, 150178.

Happer, C., \& Philo, G. (2016). New approaches to understanding the role of the news media in the formation of public attitudes and behaviours on climate change European Journal of Communication, 31 (2), 136-51.

Hope, M. (2014, 10 ${ }^{\text {th }}$ March). Analysis: UK newspaper coverage of climate change hits 12 month high, Carbon Brief. https://www.carbonbrief.org/analysis-uk-newspaper-coverage-ofclimate-change-hits-12-month-high

House of Commons Science and Technology Committee (2014). Communicating climate science.https://publications.parliament.uk/pa/cm201314/cmselect/cmsctech/254/254.pdf

Howarth, C. C., \& Sharman, A. G. (2015). Labeling opinions in the climate debate: A critical review. Wiley Interdisciplinary Reviews: Climate Change, 6, 239-254.

Kahan, D.M., Jenkins-Smith, H., \& Braman, D. (2011). Cultural cognition of scientific consensus. Journal of Risk Research, 14, 147-174. 
McCright, A. M., Dunlap, R. E., \& Marquart-Pyatt, S. T. (2016). Political ideology and views about climate change in the European Union. Environmental Politics, 25(2), 338-358.

Newman, N., Fletcher, R., Levy, D., \& Nielsen, R. K. (2016). Reuters institute digital news report (RISJ: Oxford). Retrieved from

http://reutersinstitute.politics.ox.ac.uk/sites/default/files/Digital-News-Report-2016.pdf.

O’Neill, S. J. (2013). Image matters: Climate change imagery in US, UK and Australian newspapers. Geoforum, 49, 10-19.

O'Neill, S., \& Nicholson-Cole, S. (2009). "Fear won't do it" Promoting positive engagement with climate change through visual and iconic representations. Science Communication, 30(3), 355-379.

Painter, J. (2010). Summoned by science: Reporting climate change at Copenhagen and beyond. University of Oxford: Reuters Institute for the Study of Journalism.

Painter, J. (2011). Poles apart: The international reporting of climate scepticism. Oxford: Reuters Institute for the Study of Journalism.

Painter, J.; Erviti, Carmen, M., Fletcher, R., Howarth, C., Kristiansen, S., Bienvenido, L., Oukrat, A., Russell, A., \& Schäfer, M. S. (2016). Something old, something new: Digital media and the coverage of climate change. Oxford: Reuters Institute for the Study of Journalism.

Painter, J., \& Gavin, N. T. (2016). Climate skepticism in British newspapers, 2007-2011. Environmental Communication. 10(4), 432-452.

Philo, G., \& Happer, C. (2013). Communicating climate change and energy security: New methods in understanding audiences. London: Routledge.

Pidgeon, N. (2012). Public understanding of, and attitudes to, climate change: UK and international perspectives and policy. Climate Policy, 12(sup01), S85-S106.

Pidgeon, N. F., Lorenzoni, I., \& Poortinga, W. (2008). Climate change or nuclear power-No thanks! A quantitative study of public perceptions and risk framing in Britain. Global Environmental Change, 18(1), 69-85.

Poortinga, W., Spence, A., Whitmarsh, L., Capstick, S., \& Pidgeon, N. F. (2011). Uncertain climate: An investigation into public scepticism about anthropogenic climate change. Global Environmental Change, 21, 1015-1024.

Poortinga, W., Pidgeon, N.F., Capstick, S. and Aoyagi, M. (2014) Public Attitudes to Nuclear Power and Climate Change in Britain Two Years after the Fukushima Accident - Synthesis Report. UKERC: London. 
Rahmstorf, S. (2004). The climate sceptics. Potsdam Institute for Climate Impact Research, Potsdam.

http://www.pikpotsdam.de/stefan/Publications/Other/rahmstorf_climate_sceptics_2004.pdf.

Romsdahl, R. J., Kirilenko, A., Wood, R. S., \& Hultquist, A. (2017). Assessing national discourse and local governance framing of climate change for adaptation in the United Kingdom. Environmental Communication, 11(4), 515-536.

Schlichting I. (2013). Strategic framing of climate change by industry actors: a meta-analysis, Environmental Communication, 7 (4), 493-511.

Schmid-Petri, H. (2017). Do conservative media provide a forum for skeptical voices? The link between ideology and the coverage of climate change in British, German, and Swiss newspapers. Environmental Communication, 11(4), 554-567.

Schmid-Petri, H., \& Arlt, D. (2016). Constructing an illusion of scientific uncertainty? Framing climate change in German and British print media. Communications: The European Journal of Communication Research, 41(3), 265-289.

Smith, N. W., \& Joffe, H. (2009). Climate change in the British press: The role of the visual. Journal of Risk Research, 12(5), 647-663.

Steentjes, K., Pidgeon, N., Poortinga, W., Corner, A., Arnold, A., Böhm, G., Mays, C., Poumadère, M., Ruddat, M., Scheer, D., Sonnberger, M., Tvinnereim, E. (2017). European perceptions of climate change: Topline findings of a survey conducted in four European countries in 2016. Cardiff: Cardiff University.

van Rensburg, W. (2015). Climate change scepticism: A conceptual re-evaluation. SAGE Open, April-June, 5, 2.

Ward, B. (2015, 22 October). UK Government failing to lead on climate communication. Huffington Post. http://www.huffingtonpost.co.uk/bob-ward/climate-change_b_8347246.html Whitmarsh, L. (2011). Scepticism and uncertainty about climate change: Dimensions, determinants and change over time. Global Environmental Change, 21(2), 690-700.

Whitmarsh, L., O'Neill, S., \& Lorenzoni, I. (eds.) (2010). Engaging the public with climate change: behaviour change and communication. London: Earthscan. 